\title{
Use of recombinant human granulocyte- macrophage colony stimulating factor in an infant with reticular dysgenesis
}

\author{
C. Azcona \\ V. Alzina \\ P. Barona \\ L. Sierrasesúmaga \\ I. Villa-Elízaga
}

Department of Paediatrics, University Clinic of Navarra, Faculty of Medicine, University of Navarra, Avda Pío XII s/n, E-31080 Pamplona, Spain

\begin{abstract}
We present the case of a 2-month-old infant with reticular dysgenesis who was treated with recombinant granulocyte-macrophage colony stimulating factor with the aim of stimulating granulopoiesis while awaiting bone marrow transplant.
\end{abstract}

\section{KEY WORDS}

Reticular dysgenesis; Granulocyte-macrophage colony stimulating factor

\author{
ABBREVIATIONS \\ - BMT bone marrow transplant \\ - RD reticular dysgenesis \\ - rG-CSF recombinant granulocyte stimulating factor \\ - rGM-CSF Recombinant granulocyte-macrophage stimulating factor WBC white \\ blood cells
}

\section{INTRODUCTION}

Reticular dysgenesis (RD) is a rare congenital disorder classified within the severe combined immunodeficiencies, characterized by impaired development of multiple haematopoietic cell lineages. In addition to the early developmental failure of both Tand B-cell lineages, growth and differentiation of myeloid cells is impaired in affected newborns. To date, bone marrow transplantation (BMT) is the only treatment [3], suggesting that RD may reflect an inherited defect shared by myeloid and lymphoid cell 
precursors. It has been demonstrated that recombinant granulocyte-monocyte colonystimulating factor (rGM-CSF) is a potent stimulator of myelopoiesis in vivo in patients with acquired immunodeficiency syndrome, myelodysplastic syndromes, aplastic anaemia, lymphoproliferative disorders, acquired agranulocytosis, and in patients who have received chemotherapy or autologous BMT [4]. In an attempt to stimulate granulopoiesis, our patient was treated with rGM-CSF while awaiting a BMT. We observed a positive response at the beginning of the treatment.

\section{CASE REPORT}

A 2-month-old white male newborn from non-consanguineous parents was diagnosed as having RD at 1 month of age. There was no particular relevant family history except for recurrent furunculosis in his mother. He had a healthy sister. He presented with fever, leucopenia, neutropenia and diarrhoea during his $1^{\text {st }}$ month of life. He suffered from a dilated cardiomyopathy. At 1 month of age the total white blood cell count (WBC) was $0.92 \times 10^{9} / 1\left(0.115 \times 10^{9} / 1\right.$ neutrophils, $0.4 \times 10^{9} / 1$ lymphocytes and $0.41 \times 10^{9} / 1$ monocytes). He had hypogammaglobulinaemia (Ig G 126 mg\%, Ig A $3.5 \mathrm{mg} \%$, Ig M 5 $\mathrm{mg} \%$ ). Forssman antibodies and the isohaemagglutinins were negative. A bone marrow examination showed almost total absence of myeloid series cells with some cells resembling lymphoblasts. However, cells of erythroid and megakaryocytic origin were present at all stages of maturation. Bone marrow immunophenotype was: A1, A11, B8, B18, BW6, DR3, DRW52. Peripheral blood lymphocyte phenotype was as follows: CD3 18\%, CD4 15\%, CD8 1\%, CD19 41\%, CD20 51\%, DR 42\%, CD10 35\%, CD44\%, CD16 10\%. The erythrocyte enzymes adenosindeaminase and purine nucleoside phosphorylase were positive, TdT was negative. Human immunodeficiency virus antibodies were negative. Lymphoid proliferation mitogen tests were negative. Postmortem we could prove that the thymic gland was hypoplastic, showing a lymphoid depletion which was also seen in other lymphatic organs (spleen, nodes and lymphoid mucosal tissues). These results were consistent with a diagnosis of severe combined immunodeficiency due to reticular dysgenesis.

While a suitable donor was being sought within the family in order to perform a BMT, the patient was treated with rGM-CSF given by intravenous infusion (in $1 \mathrm{~h}$ ). The initial dose was $4 \mu \mathrm{g} / \mathrm{kg}$ per day increasing progressively up to a maximum dose of $15 \mu \mathrm{g} / \mathrm{kg}$ per day on day 15 of treatment. Then, owing to adverse effects (vomiting related to dose) we decreased the dose to $10 \mu \mathrm{g} / \mathrm{kg}$ per day until the $20^{\text {th }}$ day of treatment, as is shown in Fig. 1. The total WBC increased from $0.92 \times 10^{9} / 1$ (24\% neutrophils) to $1.9 \mathrm{x}$ $10^{9} / 1\left(52.9 \%\right.$ neutrophils) on the $10^{\text {th }}$ day of treatment. On the $15^{\text {th }}$ day, the WBC was $1.6 \times 10^{9} / 1$ (51\% neutrophils). Twelve days after finishing the treatment, we observed a decrease in the WBC. For this reason we decided to reintroduce the treatment at the final dose given during the first phase of the treatment; in this second period we observed no marked modification in the leucocytes, except for an increase in the number of eosinophils, and the treatment was discontinued on the $23^{\text {rd }}$ day. During the treatment we did not observe any severe side-effects. The patient presented: arterial hypertension during the $1^{\text {st }}$ and $2^{\text {nd }}$ day of treatment related to the time of infusion, and vomiting, which started at the $2^{\text {nd }}$ day of treatment and increased relative to the dose. During this second phase the patient suffered a further deterioration due to severe infections caused by cytomegalovirus and Aspergillus fumigatus which caused his death at the age of 5 months. 


\section{DISCUSSION}

In most cases of idiopathic congenital neutropenia, rGM-CSF increases the number of functional leucocytes, due mainly to eosinophils [5, 6,]. However most children with congenital neuropenia treated with recombinant granulocyte stimulating factor (rG$\mathrm{CSF}$ ) have responded with a large increase in the number of functional neutrophils [1, 6]. In contrast, Bujan et al. [2], did not meet with a positive response when applying rG$\mathrm{CSF}$ to a patient with RD. In an attempt to stimulate granulopoiesis and to prevent a clinical deterioration while expecting to perform a BMT, we decided to administer rGM-CSF to our patient. Treatment with rGM-CSF in this case elicited leucocytes consisting primarily of neutrophils and lymphocytes in the first period to treatment. A marked eosinophilia was observed at the beginning of the second phase of treatment.

This moderately good response in our patient suggests that the haematopoietic precursor common to both myeloid and lymphoid origin is more sensitive to GM-CSF than to GCSF. As has recently been stated by Bujan et al. [2], treatment of such patients with a growth factor which acts at an earlier stage would be of interest. We should like to suggest the possibility of giving this myelopoietic factor or an earlier acting factor (IL3 ) in patients suffering from severe combined immunodeficiency in order to prevent clinical deterioration while searching for a suitable donor for BMT, or waiting for the resolution of a temporary problem that rules out BMT.

\section{REFERENCES}

1. Bonilla MA, Gillio AP, Ruggeiro M, Kernan NA, Brochstein JA, Abbouud MA, Fumaggalli L, Vincent M, Welte K, Souza LM, O'Reilly RJ (1989) Effects of recombinant human granulocyte colony stimulating factor on neutropenia in a patient with congenital agranulocytosis. N Engl J Med 320: 1574-1580

2. Bujan W, Ferster A, Azzi N, Devalck C, Leriche A, Sariban E (1992) Use of recombinant human granulocyte colony stimulating factor in reticular dysgenesis. Br J Haematol 81(1): 128-130

3. Fischer A, Landais P, Friedrich W, Morgan G, Gerritsen B, Fasth A, Porta F, Griscelli C, Goldman SF, Levinsky R, Vossen J (1990) European experience of bone marrow transplantation of severe combined immunodeficiency. Lancet 336:850-854

4. Lieschke GJ, Burgess AW (1992) Granulocytes colony-stimulating factor and granulocyte-macrophage colony-stimulating factor (first and second parts). N Engl J Med 327(1): 28-35, 327(2): 99-106

5. Vadhan-Raj S, Jeha SS, Buescher S, LeMaistre A, Yee G, Lu L, Lloreta J, Hoots WK, Hittelman WN, Gutterman J, Broxmeyer HE (1990) Stimulation of myelopoiesis in a patient with con-genital neutropenia: biology and nature of response to recombinant human granulocyte-macrophage colony-stimulating factor. Blood 75(4): 858-868

6. Welte K, Zeider C, Reiter A, Muller W, Odenwald E, Souza L, Riehm H (1990) Differential effects of granulocyte-macrophage colony-stimulating factor and granulocyte colony-stimulating factor in children with severe congenital neutropenia. Blood 75(5): 1056-1063 


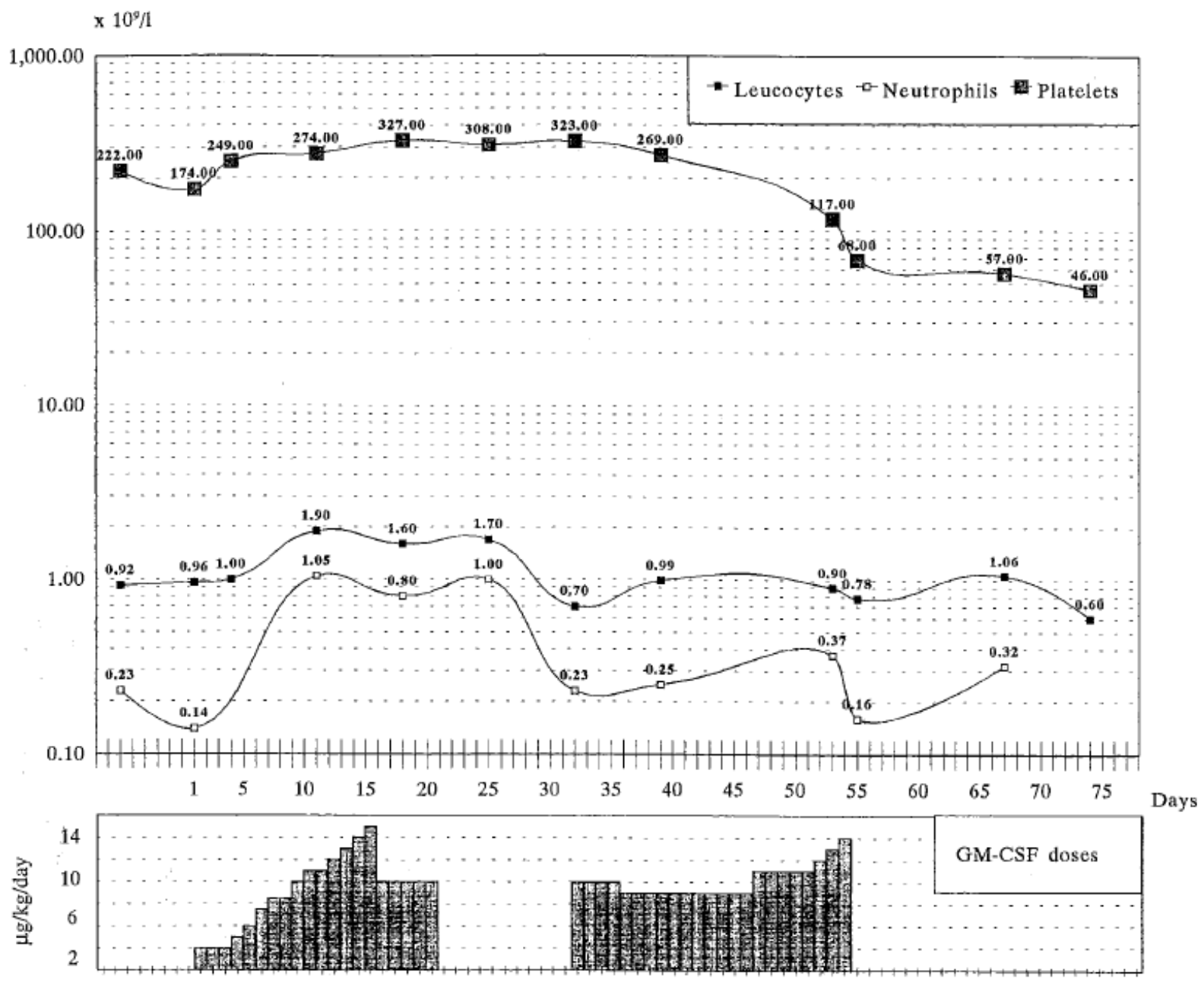

Figure 1. Effects of rGM-CSF treatment on leucocytes, neutrophils and platelets. 